\title{
Anabolic steroids, acute myocardial infarction and polycythemia: A case report and review of the literature
}

\author{
Kathleen Stergiopoulos' \\ Joseph J Brennan² \\ Robin Mathews' \\ John F Setaro ${ }^{2}$ \\ Smadar Kort ${ }^{1}$ \\ 'Division of Cardiovascular Medicine, \\ Department of Internal Medicine, \\ Stony Brook University Medical \\ Center, Stony Brook, NY, USA; \\ 2Division of Cardiovascular Medicine, \\ Department of Internal Medicine, Yale \\ University, School of Medicine, \\ New Haven, CT, USA
}

\begin{abstract}
The association between testosterone-replacement therapy and cardiovascular risk remains unclear with most reports suggesting a neutral or possibly beneficial effect of the hormone in men and women. However, several cardiovascular complications including hypertension, cardiomyopathy, stroke, pulmonary embolism, fatal and nonfatal arrhythmias, and myocardial infarction have been reported with supraphysiologic doses of anabolic steroids. We report a case of an acute ST-segment elevation myocardial infarction in a patient with traditional cardiac risk factors using supraphysiologic doses of supplemental, intramuscular testosterone. In addition, this patient also had polycythemia, likely secondary to high-dose testosterone. The patient underwent successful percutaneous intervention of the right coronary artery. Phlebotomy was used to treat the polycythemia acutely. We suggest that the chronic and recent "stacked" use of intramuscular testosterone as well as the resultant polycythemia and likely increased plasma viscosity may have been contributing factors to this cardiovascular event, in addition to traditional coronary risk factors. Physicians and patients should be aware of the clinical consequences of anabolic steroid abuse.
\end{abstract}

Keywords: acute myocardial infarction, anabolic steroid use, polycythemia

Supraphysiologic doses of anabolic-androgenic steroids (AAS), which include more than 30 natural and synthetic derivatives of testosterone, may cause a wide spectrum of clinical sequalae. There have been a few case reports in the literature suggesting an association of intracoronary thrombosis, sudden death, myocardial necrosis, stroke and cardiomyopathy as possible sequelae of the use of supraphysiologic doses of anabolic steroids (McNutt et al 1988; Nieminen et al 1996; Dhar et al 2005).

The use of testosterone supplementation in physiologic doses has expanded in the last decade to include indications, such as stimulation of appetite in cachexia, improvement in libido and mood, as well as treatment of hypogonadism (Rhoden and Morgentaler 2004). Moreover, testosterone has been used in the treatment of reduced muscle mass and bone density as well as anemia. The role testosterone may play in the development of cardiovascular disease has increasingly become the subject of current interest (Choi and McLaughlin 2007). Although the data for physiologic doses of testosterone replacement therapy have not demonstrated an increased incidence of cardiovascular event, long-term effects on cardiovascular health requires prospective, large-scale, randomized trials.

Testosterone stimulates erythropoiesis, particularly in high doses (Fried and Gurney 1968). Drastic elevations of hematocrit may be detrimental to patients with underlying coronary, cerebral or peripheral vascular disease by possibly causing an increase in blood viscosity (Basaria and Dobbs 1999; Viallard et al 2000), and increased risk 
of thrombosis. We present a case of an acute inferior wall ST segment myocardial infarction in a patient using high dose testosterone with associated polycythemia.

\section{Case report}

A 44-year-old male without prior cardiac history presented with one day of intermittent exertional, substernal chest pain culminating in rest angina. He described associated features of left shoulder pain, shortness of breath and diaphoresis. He was taking high-dose intramuscular testosterone for the previous six weeks, and intermittently for two years. In addition, he was taking sildenafil occasionally. He was a recreational weight-lifter. His cardiac risk factors included tobacco abuse and family history of early coronary artery disease. There was no family history of lipid disorder. His physical examination was remarkable for his muscular appearance and a blood pressure of 190/100. He was in mild distress with no signs of heart failure. His blood chemistry revealed a creatinine of $1.3 \mathrm{mg} / \mathrm{dl}$ and elevated liver enzymes (aspartate aminotranferease 86 units/L, and alanine aminotransferase 79 units/L). Hematologic studies noted an hemoglobin of $22 \mathrm{~g} / \mathrm{dl}$ and hematocrit of $63 \%$. His platelet count was normal with a mildly elevated white blood count. His creatinine kinase (CK), CK-MB, and troponin were within normal limits on presentation. An electrocardiogram revealed sinus bradycardia, left ventricular hypertrophy, an acute inferior injury pattern with ST-segment elevation, and anterolateral ischemia. Ventricular bigeminy was also noted (Figure 1).
Emergent cardiac catheterization was then performed via the right femoral artery. Selective left coronary angiography revealed a diffusely diseased left anterior descending artery (LAD) with a 95\% lesion after the takeoff of a small septal branch (Figure 2). The circumflex artery was free of significant disease. Selective right coronary angiography revealed a total occlusion at the mid-portion of the vessel with intracoronary thrombus (Figure 3). The patient underwent percutaneous transluminal coronary angioplasty (PTCA) and stent placement in the mid and distal right coronary artery vessel. The right coronary artery was notably a large, dominant vessel (Figure 4). The procedure was complicated by distal embolization, treated with intracoronary adenosine and glycoprotein IIb/IIIa inhibitor, which resulted in some angiographic improvement. Clopidogrel (300 mg loading dose and $75 \mathrm{mg}$ thereafter) was initiated immediately. The patient's peak CK and CK-MB were 8830 units/L and 1800 units/L, respectively. A transthoracic echocardiogram demonstrated that the patient's left ventricular systolic function was moderately reduced with inferior and inferoseptal akinesis, and inferolateral hypokinesis. The ejection fraction was $35 \%$. Successful percutaneous intervention and stent placement were performed on the lesion in his left anterior descending artery on the following day. The patient was phlebotomized until his resultant hematocrit was $45 \%$. Hematological workup for malignancy was negative. Total cholesterol was $219 \mathrm{mg} / \mathrm{dl}$, low-density lipoprotein (LDL) cholesterol was $154 \mathrm{mg} / \mathrm{dl}$, and high-density lipoprotein (HDL) $50 \mathrm{mg} / \mathrm{dl}$.

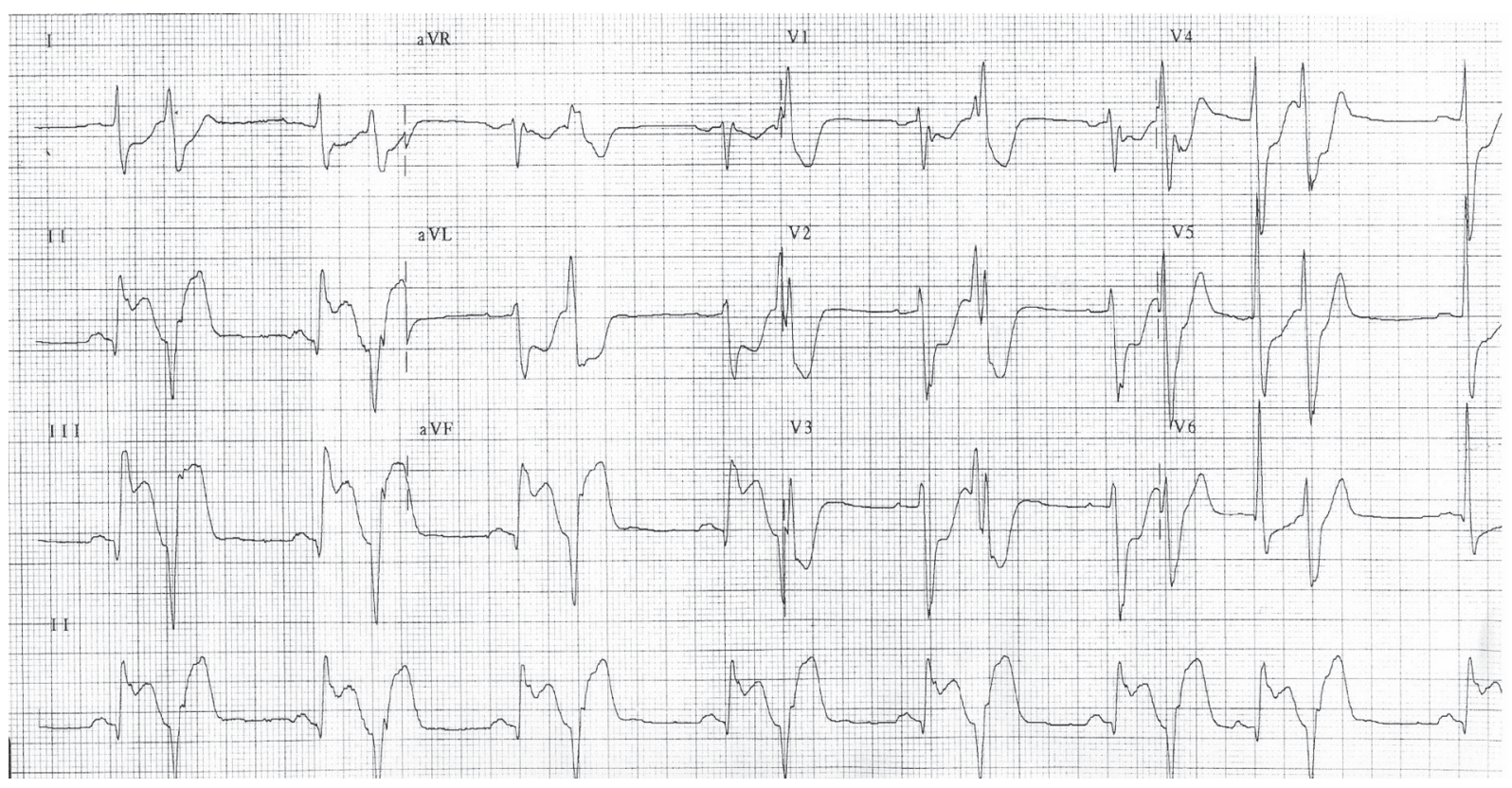

Figure I The patient's electrocardiogram on presentation. 


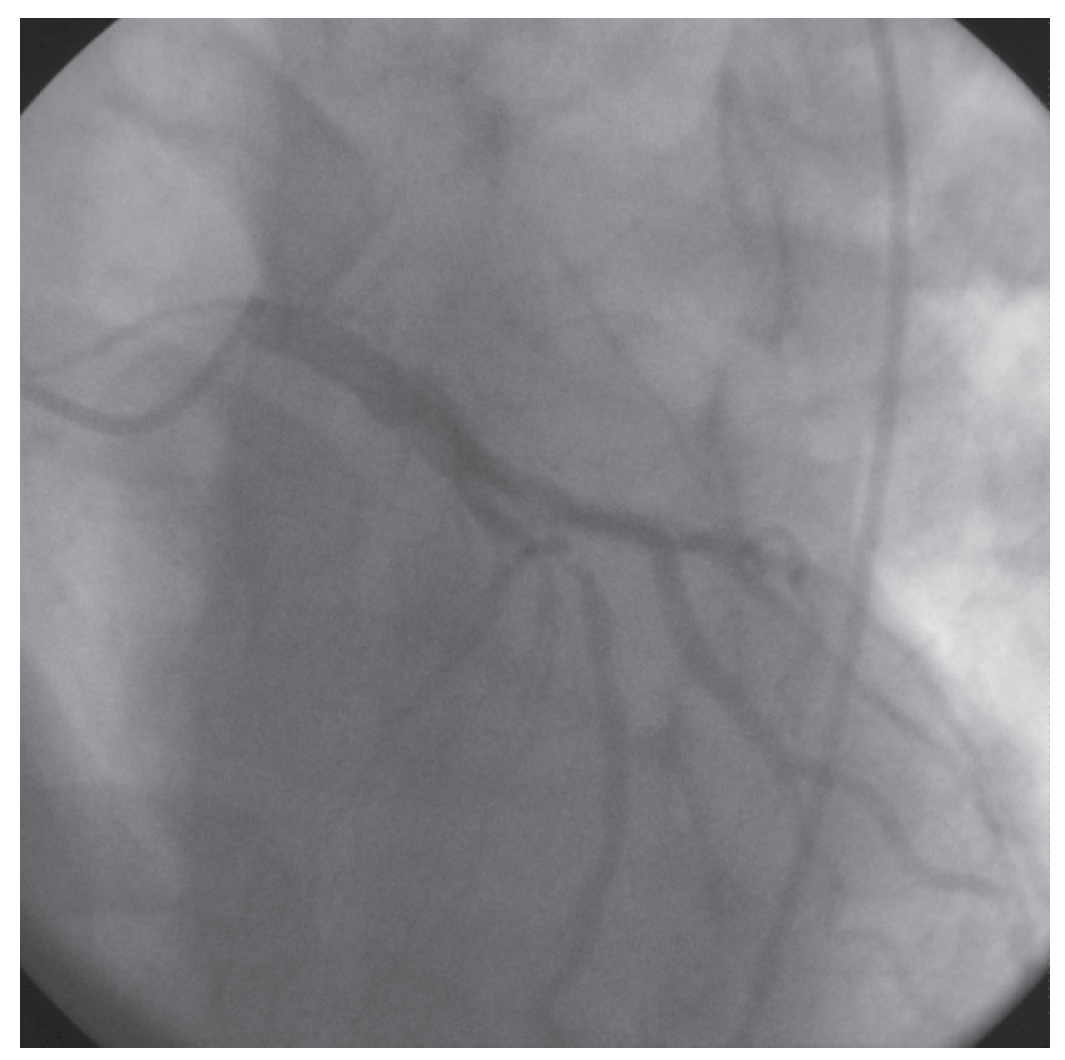

Figure $2 \mathrm{An}$ anterior-posterior view of the left coronary system. The left anterior artery demonstrates a $95 \%$ stenosis after the first septal branch.

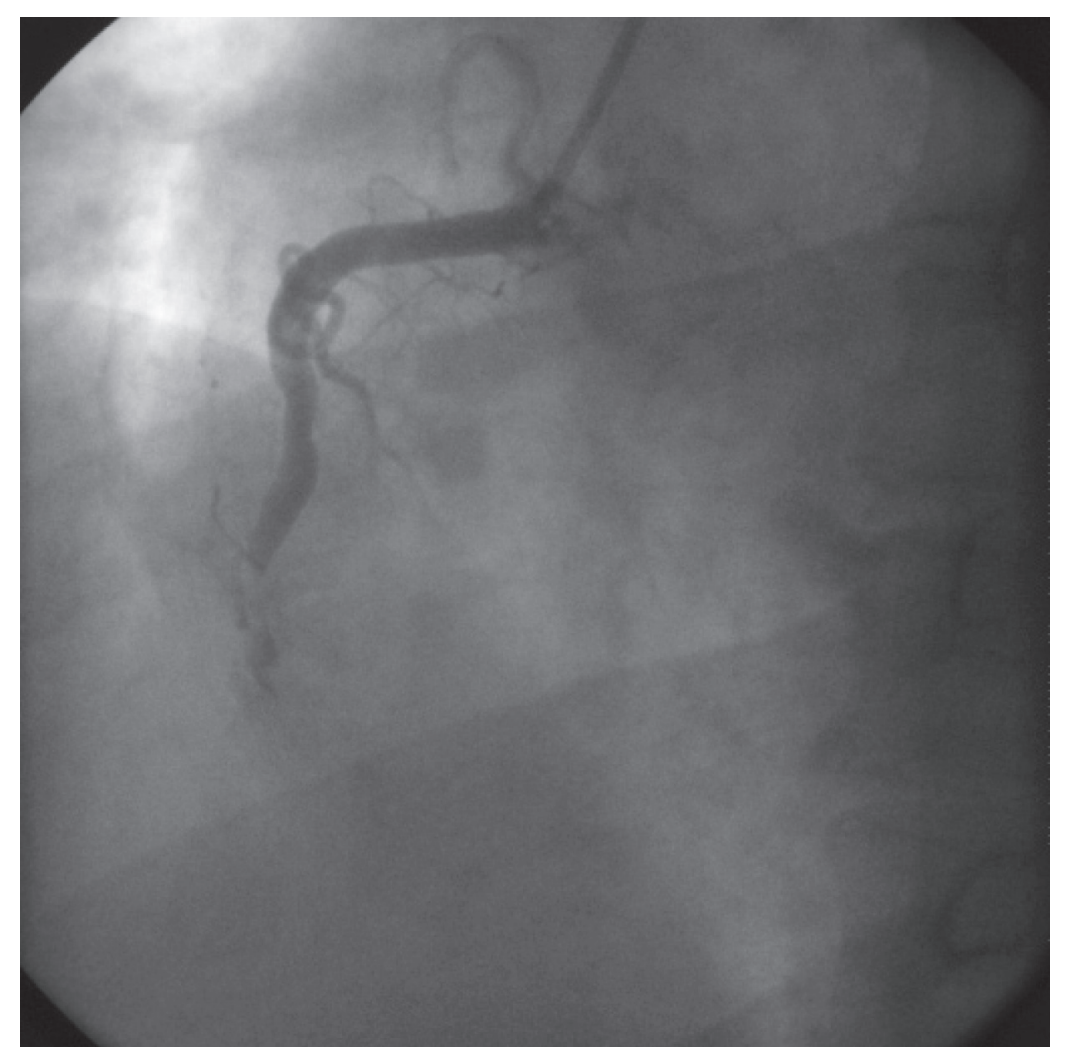

Figure $3 \mathrm{~A}$ left anterior oblique view of the right coronary system, demonstrating a total occlusion of the mid right coronary artery with thrombus. 


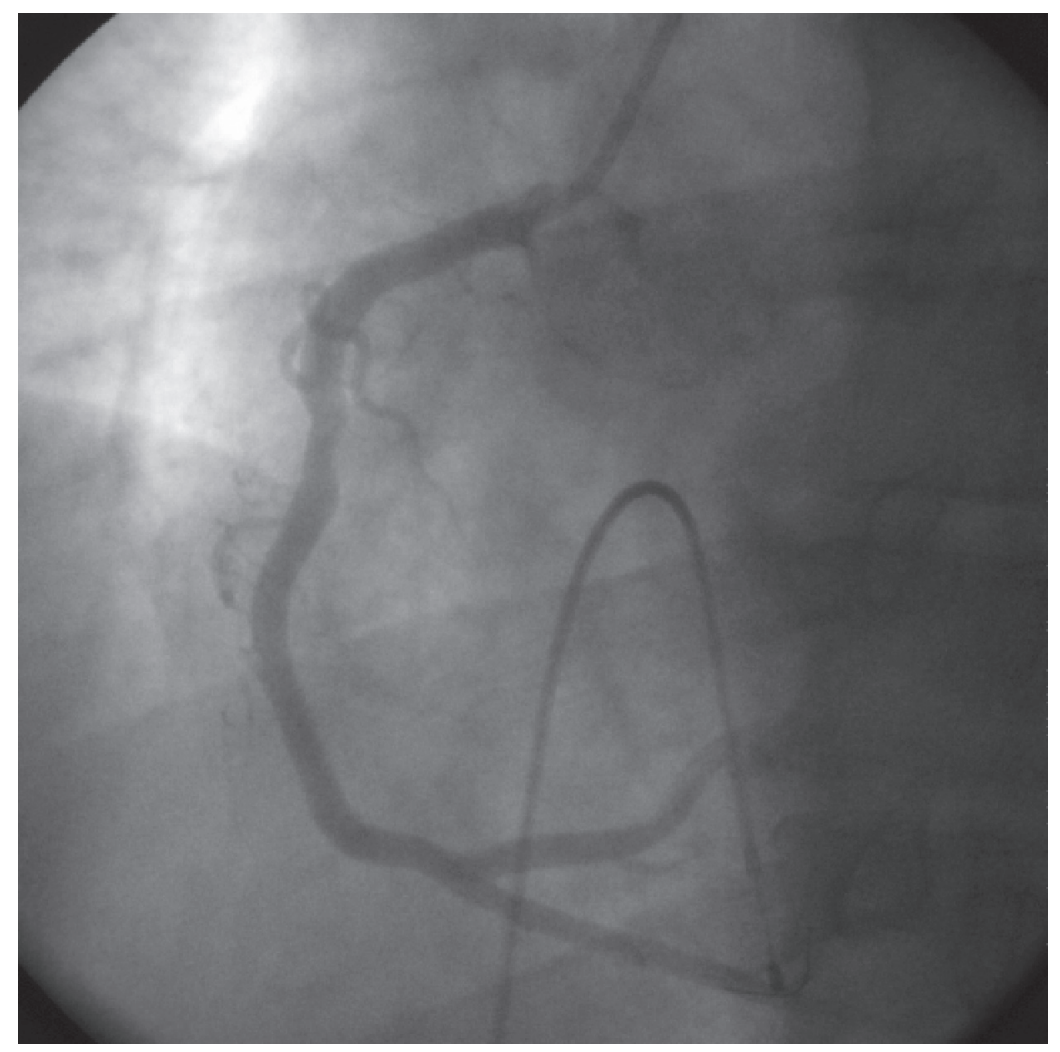

Figure $4 \mathrm{~A}$ left anterior oblique view of the right coronary artery after percutaneous intervention.

Standard medical therapy for acute myocardial infarction was initiated following the intervention and included aspirin, clopidogrel, beta-blocker, statin, and angiotensin converting enzyme inhibitor.

\section{Discussion and review of the literature}

Anabolic androgenic steroid use has increased over the past decade, despite its potential for adverse effects. They continue to be used by Olympic level athletes, and have even spread to high school level athletes, noncompetitive bodybuilders and recreational athletes (Sullivan et al 1998; Dhar et al 2007). Unfortunately, the data on the use of high dose anabolic steroids in humans are mainly offered as case reports or small studies that lack adequate control groups. In addition, the data available in the literature does not account for the steroid type(s) or dose, as neither may be known. Patients also may be taking concomitant stimulants, such as ephedra, which can confound data and the potential for adverse events. It is likely that the frequency of cardiac events is underreported in the medical literature.

Supplemental or physiologic doses of testosterone have noticed expanded use in medical practice recently.
Testosterone is a potent ligand of the human androgen receptor and therefore, can modulate cellular functions such as transcription, translation and enzymatic function in skeletal and myocardial tissue. However, these functions can affect numerous other tissues. Other common potential adverse effects include infertility, hepatotoxicity, psychological abnormalities, and gynecomastia (Rhoden and Mortgentaler 2004).

Several case reports describe the deleterious cardiac effects of anabolic steroids including its potentially atherogenic and thrombotic properties. These range from lipid disorders to acute myocardial infarction and sudden cardiac death (Kennedy and Lawrence 1993; Hourigan et al 1998; Fineschi et al 2001; Wysoczanski et al 2008). Thromboembolic phenomenoma, intracardiac and peripherally, have been described (McCarthy et al 2000). Cardiomyopathy, cardiomegaly and biventricular dilatation have been associated with AAS use. Mewis and colleagues (1996) demonstrate a case report of a young bodybuilder with severe coronary artery disease with a two-year history of chronic anabolic steroid use. A case control study of 62 male competitive powerlifters notes a possible increase in premature mortality compared with controls (12.9\% versus $3.1 \%)$ Parssinen et al 2000). 
Potential mechanisms of cardiovascular toxicity of AAS include: atherogenic, thrombotic, vasospastic, and direct myocardial injury. The atherogenic model involves changes to lipid metabolism, including reductions in HDL levels and elevations in LDL (Melchert and Welder 1995; Feller et al 2003). Although difficult to quantitate, the increased risk of cardiac disease may be as high 3-fold among individuals who use AAS (Melchert and Welder 1995; Sullivan et al 1998).

Development of an atheromatous plaque perpetuates endothelial dysfunction and promotes platelet aggregation and intracoronary thrombus formation (Ajayi et al 1995; Nieminen et al 1996). AAS may cause a hypercoagulable state, by an increase in production of thromboxane $\mathrm{A}_{2}$ and platelet thromboxane $A_{2}$ receptor density as well as aggregation responses and a decrease in production of prostaglandins (Ajayi et al 1995). Moreover, a component of endothelial dysfunction has been proposed, which may contribute to abnormal vessel reactivity. However, testosterone in physiologic doses may even be beneficial in patients with angina (English et al 2000), have higher ischemic thresholds and improved quality of life (Malkin et al 2004). Short-term intracoronary administration of testosterone induces coronary artery dilation and increases coronary blood flow in men with established coronary artery disease (Webb et al 1999). Therefore, an interplay of endogenous factors of the patient's risk profile as well as the testosterone dosing may be issues of whether adverse events occur.

Direct myocardial cell injury may occur by disruption of mitochondria and induction of intrafibrillar collagen dysplasia (Melchert and Welder 1995; Sullivan et al 1998). Cellular injury results in fibrosis, which can be a potential nidus for ventricular arrhythmias. Patients commonly develop left ventricular hypertrophy, which may be related to hypertension, another adverse effect of AAS.

Erythrocytosis has been reported as a potential effect of testosterone, which can be beneficial in patients with anemia. However, dramatic elevations in hematocrit may be detrimental to patients with underlying coronary artery disease, as this may increase blood viscosity (Basaria and Dobbs 1999; Viallard et al 2000). The greatest risk of erythrocytosis occurs with injectable forms of testosterone compared with transdermal preparations, especially in supraphysiologic doses. An increase of up to $44 \%$ of the baseline hematocrit has been reported (Dobs et al 1999).

We report for the first time an unusual case of an acute ST segment elevation myocardial infarction immediately following supraphysiologic "stacked" doses of intramuscular testosterone in a patient with known risk factors for coronary artery disease with associated dramatic polycythemia. We propose an association and potential interplay of traditional cardiovascular risk factors, high dose testosterone use, and possibly elevated plasma viscosity as possible contributors to this cardiovascular event (Basaria and Dobbs 1999; Viallard et al 2000).

\section{Disclosure}

The authors report no conflicts of interest in this work.

\section{References}

Ajayi AAL, Mathur R, Halushka PV. 1995. Testosterone increase human platelet thromboxane $\mathrm{A} 2$ receptor density and aggregation responses. Circulation, 91:2742-7.

Basaria S, Dobs AS. 1999. Risks versus benefits of testosterone therapy in elderly men. Drugs Aging, 15:131-42.

Choi BG, McLaughlin MA. 2007. Why men's hearts break: cardiovascular effects of sex steroids. Endocrinol Metab Clin N Am, 36:365-77.

Dhar R, Stout W, Link MS, et al. 2005. Cardiovascular toxicities of performanceenhancing substances in sports. Mayo Clin Proc, 80:1307-15.

Dobs AS, Meikle AW, Arver S, et al. 1999. Pharmacokinetics, efficacy, and safety of a permeation-enhanced testerosterone in comparison with bi-weekly injections of testerosterone enanthate for the treatment of hypogonadal men. J Clin Endocrinol Metab, 64:3469-78.

English KM, Mandour O, Steeds RP, et al. 2000. Men with coronary artery disease have lower levels of androgens than men with normal coronary angiograms. Eur Heart J, 21:890-4.

English KM, Steeds RP, Jones TH, et al. 2000. Low-dose transdermal testosterone therapy improves angina threshold in me with chronic stable angina: a randomized, double-blind, placebo-controlled study. Circulation, 102:1906-11.

Feller AA, Mylonakis E, Rich JD. 2002. Medical complications of anabolic steroids. Med Health R I, 85:338-40.

Fineschi V, Baroldi G, Monciotti F, et al. 2001. Anabolic steroid abuse and cardiac sudden death: a pathologic study. Arch Pathol Lab Med, $125: 253-5$.

Fried W, Gurney CW. 1968. The erythropoietic-stimulating effects of androgens. Ann NY Acad Sci, 149:356-65.

Hourigan LA, Rainbird AJ, Dooris M. 1998. Intracoronary stenting for acute myocardial infarction (AMI) in a 24-year-old man using anabolic androgenic steroids. Aust N Z J Med, 28:838-9.

Kabakci G, Yidirir A, Can I, et al. 1999. Relationship between endogenous sex hormone levels, lipoproteins and coronary atherosclerosis in men undergoing coronary angiography. Cardiology, 92:221-5.

Kennedy MC, Lawrence C. 1993. Anabolic steroid abuse and cardiac death. Med J Aust, 158:346-8.

McNutt RA, Ferenchick GS, Kirlin PC, et al. 1988. Acute myocardial infarction in a 22-year-old world class weight lifter using anabolic steroids. Am J Cardiol, 62:164.

Malkin CJ, Pugh PJ, Morris PD, et al. 2004. Testosterone replacement in hypogonadal men with angina improves ischaemic threshold and quality of life. Heart, 90:871-6.

McCarthy K, Tang AT, Dalrymple-Hay MJ, et al. 2000. Ventricular thrombosis and systemic embolism in bodybuilders:etiology and management. Ann Thorac Surg, 70:658-60.

Melchert RB, Welder AA. 1995. Cardiovascular effects of androgenicanabolic steroids. Med Sci Sports Exerc, 27:1252-62.

Mewis C, Spyridopoulos I, Kuhlkamp V, et al. 1996. Manifestation of severe coronary heart disease after anabolic drug abuse. Clin Cardiol, 19:153-5.

Nieminen MS, Ramo MP, Viitasalo M, et al. 1996. Serious cardiovascular side effects of large doses of anabolic steroids in weight lifters. Eur Heart J, 17:1576-83. 
Parssinen M, Kujala U, Vartiainen E, et al. 2000. Increased premature mortality of competitive powerlifters suspected to have used anabolic agents. Int J Sports Med, 21:225-7.

Rhoden EL, Morgentaler A. 2004. Risks of testosterone-replacement therapy and recommendations for monitoring. New Engl J Med, 350:482-92.

Sullivan ML, Martinez CM, Gennis P et al. 1998. The cardiac toxicity of anabolic steroids. Prog Cardiovasc Dis, 41:1-15.
Viallard JF, Marit G, Mercie P, et al. 2000. Polycythaemia as a complication of transdermal testosterone therapy. Br J Haematol, 110:237-8.

Webb CM, McNeil JG, Hayward CS, et al. 1999. Effects of testosterone on coronary vasomotor regulation in men with coronary heart disease. Circulation, 100:1690-6.

Wysoczanski M, Rachko M, Bergmann SR. 2008. Acute myocardial infarction in a young man using anabolic steroids. Angiology, 59:376-8. 